\title{
Una cierta tendencia en la televisión estadounidense. Evolución de la noción de autoría en el género dramático.
}

\author{
Pedro José García García \\ Universidad de Sevilla \\ http://dx.doi.org/10.12795/AdMIRA.2011.01.05
}

\begin{abstract}
Resumen
Desde los inicios de la televisión estadounidense como producto comercial, es posible identificar a los guionistas, productores y directores televisivos que han ido moldeando las distintas etapas del drama televisivo. Sin embargo, resulta una tarea compleja tratar de asignar a estas figuras una responsabilidad creativa de los productos finales, es decir, una autoría tal y como la plantearon los estudiosos de Cahiers du Cinéma. El drama televisivo estadounidense experimenta un cambio a partir de los ochenta que le convierte en proveedor de relatos capaces de competir con el cine. Este fenómeno coincide con la cada vez más importante presencia de los productores ejecutivos que controlan todos los aspectos de la producción de una serie, en lugar de ser meros enlaces entre equipo creativo y cadena. Como resultado, la televisión norteamericana se caracteriza actualmente por la presencia de grandes figuras creativas que, al igual que ocurre en el cine, presentarán estilemas de autor. Gracias al trabajo de homogeneización de un equipo de guionistas, la imagen de autor de un productor ejecutivo de televisión será más definida e identificable dentro de sus productos. De esta manera, la nueva ficción televisiva norteamericana crea 'productores estrella' que servirán como reclamo publicitario y garante de calidad y fidelidad de cara a los nuevos estrenos.
\end{abstract}

\section{Palabras clave}

Teoría de autores, televisión estadounidense, drama televisivo, productor televisivo

Surround yourself with smart, sane, talented people. Have the fun. Take the credit.

Joss Whedon (Dollhouse, DVD)

\section{Introducción}

En este trabajo revisaremos la clásica teoría de los autores desarrollada por André Bazin y la revista especializada Cahiers du Cinéma para aplicarla al medio televisivo. Esto será posible no solo porque a lo largo de la última década los reconocidos Admira no $3-2011$ 
realizadores cinematográficos -Spielberg, Cameron, Scorsese- han dado el salto a la pequeña pantalla, sino también porque la televisión norteamericana ha sido testigo en las dos últimas décadas del nacimiento de un importante número de productores y guionistas, cuyo trabajo les ha otorgado el título de autor en las publicaciones especializadas y el ámbito académico y de investigación -Bochco, Abrams, Whedon, Simon. Comprobaremos cómo la pugna por la autoría en televisión se lleva a cabo principalmente entre productores/creadores y guionistas, y trataremos de concluir cuál es la aportación de cada figura al proceso creativo de una serie de televisión de larga duración, y cuáles son los factores que permitirán la clasificación de unos y otros como autores televisivos. El corpus investigador de los años ochenta y noventa en Estados Unidos nos revela cómo la mayoría de autores atribuyen la autoría a la figura del productor ejecutivo/creador (Horace Newcomb, Robert S. Alley, 1983; David Marc, Robert J. Thompson, 1992), sin embargo, en el comienzo del siglo XXI se toma en consideración el arduo trabajo del guionista televisivo, buscando auteurs entre estas figuras en la sombra del proceso creativo en televisión (Heil, 2002) -después de todo, muchos de los productores ejecutivos más exitosos comenzaron sus carreras como guionistas.

Los intercambios de profesionales entre el cine y la televisión son cada vez más habituales. Hace un par de décadas era común que las grandes celebridades catódicas abandonasen las series televisivas para forjarse una carrera cinematográfica, y los guionistas y productores sobreviviesen como asalariados en la televisión hasta poder participar en un largometraje. Sin embargo, en la actualidad, cine y televisión disfrutan de una hermandad absoluta, y las estrellas cinematográficas $-\mathrm{y}$ nos referimos no solo a los actores, sino a los directores, productores y guionistas de renombre- no acuden a la televisión porque el cine ya no las quiera, sino porque es allí donde está la calidad. Sin embargo, no podemos ignorar el hecho de que ya desde los inicios de la ficción televisiva en Estados Unidos, los actores, guionistas, productores y directores de Hollywood trabajaban para ambos medios -recordemos la exitosa incursión televisiva del director británico Alfred Hitchcock en la televisión norteamericana con Alfred Hitchcock presenta. A pesar de esto, la televisión no logró adquirir la consideración suficiente para hacer competencia al cine a nivel creativo y de aceptación crítica hasta finales de los ochenta. E incluso cuando la televisión comenzaba a demostrar su potencial narrativo durante esta década y la siguiente, y los Admira $n^{0} 3-2011$ 
fenómenos mediáticos se sucedían uno detrás de otro -Canción triste de Hill Street, Dallas, Twin Peaks, Expediente $X$-, el medio continuaba percibiéndose como una industria secundaria y de menor categoría donde los actores en decadencia encontraban refugio para sus agonizantes carreras (Cascajosa Virino, 2005:15).

Para muchos, el drama televisivo de calidad está desplazando totalmente la atención de los estudios sobre cultura popular, que consideran que el cine ya ha alcanzado su cénit artístico, mientras que la televisión se encuentra en una etapa de florecimiento y experimentación que brinda multitud de posibilidades investigadoras. A este hecho contribuyen sin duda algunos de los nombres ya mencionados, grandes productores ejecutivos que se han planteado su obra a lo largo de los años como lo haría un autor cinematográfico. Productores como J.J. Abrams, David Simon, y en especial, Joss Whedon, no solo han generado éxitos de público y crítica para el consumo efímero de la televisión, sino que han logrado construir un complejo discurso cuyas ideas estructurantes subyacen de todas sus obras y permiten hablar de una 'filmografía' al igual que si nos refiriéramos a Woody Allen o François Truffaut. Teniendo esto en cuenta, veremos cómo es posible identificar un autoría única en muchos dramas televisivos, hallando valores estéticos, arquetipos y temas en común entre todas sus obras.

\section{La política de los autores y el medio televisivo}

Identificar un único responsable de una obra cinematográfica, a pesar del trabajo en equipo que toda película conlleva, es algo habitual, y en la mayoría de ocasiones, para hacerlo bastará con atender a la última entrada de los créditos iniciales: "dirigido por". Atribuir la responsabilidad creativa total de un filme a un nombre nace en parte de la necesidad de considerar el cine -y más recientemente la televisión- como arte, con las mismas implicaciones que la pintura, la escultura o la literatura, en las que lo habitual es que cada obra pueda ser ligada al esfuerzo individual de un artista.

La noción de autoría como algo más que una mera responsabilidad creadora -es decir, como un esfuerzo creativo y una visión personal en oposición al trabajo mecánico y la producción en cadena- nace con el trabajo de André Bazin y adquiere fuerza y presencia en los estudios sobre cine gracias a Cahiers du Cinéma. Los críticos de 
Cahiers no vacilaron en atribuir la autoría cinematográfica al director-realizador, a quien consideraban el mayor responsable del resultado final, apuntando a la puesta en escena como el aspecto que dotará a una película de su identidad y permitirá diferenciar a unos autores de otros. Esta noción de autoría se basa pues en principios estéticos y estilísticos, y en la idea del realizador como articulador del lenguaje cinematográfico a través de la planificación. Douglas Heil, investigador especializado en drama televisivo, sigue la teoría de Peter Wollen para afirmar que un metteur en scène es un guionista que además es un estilista, y cuya labor es la de disponer las ideas de otro con un estilo distintivo. Un auteur, sin embargo, impone su punto de vista sobre el material, y su trabajo es destacable gracias a una serie de motivos temáticos reconocibles, así como por el estilo con el que los expresa (2002:XV).

Como afirma Antoine de Baecque, el ejercicio realizado por Cahiers du Cinéma con su política de los autores es un culto estético a la personalidad de los directores (2003:22). Para el autor, esta teoría "es también una manera de justificar esta pasión: los textos fundadores de los Cahiers du Cinéma asocian de un modo irreversible la adhesión a un cineasta y la comprensión de un universo formal, personal; para decirlo en pocas palabras: su visión del mundo" (2003:20), a lo que añade que "la política de los autores es esta manera de apreciar y de defender el trabajo de ciertos cineastas en virtud de una visión y de una comprensión de su talento como realizadores" (2003:22). Esta teoría entraña un riesgo, también expuesto por de Baecque:

Es necesario a veces hablar de una dogmatización de la política de los autores construida alrededor de un doble proceso: la autorificación sin medida y el arrebato del elogio. En este sentido, a menudo la crítica no es más que un testimonio de la consagración del autor de películas: ya no descubre un filme, no hace más que identificarlo y autentificarlo como enseña y rúbrica de un autor. El crítico se ha transformado en experto de una política de consagración (2003:23-24).

Douglas Heil lo expresa de otra manera y aporta una visión más completa: “Auterism inspired students with the assurance that the development and dissemination of ideas through media was not incompatible with commercial formats and a well-paying job. The concept does have its liabilities: it can encourage egotism, self-indulgence, and uncritical hero worship. But it also helps generate urgent, thoughtful work" (2002:XIV). Como vemos, es habitual atribuir la autoría -entendida como auteurism 
y no authorship- a un director como resultado de la desmedida admiración hacia su trabajo.

$\mathrm{Si}$ bien es cierto que esto puede ocurrir en las publicaciones especializadas, no podemos olvidar que esta exaltación ante la obra de un realizador es habitualmente posterior a su consideración como autor. Es decir, la admiración y lealtad profesada a un director de cine resulta en la mayoría de casos en el placer del reconocimiento de los rasgos del autor, previamente establecidos como estilemas de su personalidad cinematográfica. Por otra parte, es cierto que desde las publicaciones especializadas es muy común precipitarse - debido al deseo de permanecer a la vanguardia- a la hora de 'descubrir' nuevos talentos, atribuyéndoles la etiqueta de auteur con tan solo una o dos obras. En estos casos, el elogio puede interponerse a la hora de valorar el trabajo de un autor, restando rigor al crítico.

Javier Maqua afirma que la atribución del título de autor al director de la película se debía a que esta figura era quien aportaba la unidad necesaria al trabajo en equipo de distintos profesionales -sonidistas, cámaras, fotógrafos, escenógrafos-, quien daba forma con la planificación, la dirección de actores y quien poseía el poder sobre el resto de miembros del equipo: "Era, sobre todo, quien ponía en escena y (salvo intervención del productor) quien tenía la última palabra, cuestión de poder en ambos casos: dueño, por una parte, de un saber especializado (el de la puesta en escena) y por otra, de unas dotes o bastón de mando que obligaba al resto de los que intervenían en la película a la obediencia" (1992:75). En este sentido, algunos autores se han aproximado a la problemática de la autoría en televisión desde un punto de vista puramente narrativo, a través de la teoría de la enunciación, para identificar al enunciador del texto televisivo como el "autor real" (Wolf, 1987). Esta figura se sitúa fuera del texto y se identifica con el editor o el director, que se encargan de transmitir el mensaje al enunciatario (Gordillo, 2009:58).

Partiendo de las ideas expuestas por Cahiers, el realizador cinematográfico sería como un director de orquesta, organizador de un esfuerzo colectivo, alguien que unifica la partitura escrita por otro y el trabajo de un equipo de músicos contratados para obtener un resultado final. Y sin embargo, al director de orquesta nunca se le considerará autor de la pieza interpretada. Este manejo de la gramaticalidad del director de cine es en definitiva lo que le convierte en el único representante de la Admira no $3-2011$ 
obra, en el único nombre que podrá aparecer tras la expresión "una película de". Según François Truffaut, uno de los autores cinematográficos más importantes de la historia del cine -incluido en la compilación de De Baecque sobre la política de los autores-, el director cinematográfico, para ser considerado autor, deberá ser capaz de aportar una visión unificadora -tanto visual como temáticamente- del trabajo realizado por otros -historias escritas por distintos guionistas y rodadas para productoras muy diversas. Como afirma el autor en su artículo para el $n^{0} 31$ de Cahiers du Cinéma, "Une certaine tendance du cinéma français" (1954), los metteurs en scène son, y desean ser, responsables de los guiones y los diálogos que "ilustran".

El hecho de que un director como Fritz Lang cuente siempre la misma historia en la etapa norteamericana de su cinematografía, a pesar de que sus películas estén escritas por distintos guionistas, hace a Truffaut plantearse que el director alemán "podría ser un verdadero autor de películas, y que si sus temas, sus historias, toman, para llegar hasta nosotros, la apariencia banal de un thriller de serie, de un filme bélico o de un western, hay que ver quizás en ello el signo de la gran identidad de un cine que no siente la necesidad de colgarse tentadoras etiquetas" (2003:30). No obstante, esta idea nos hace pensar que Truffaut podría estar siendo víctima del riesgo que según de Baecque entraña la política de autores: la glorificación de un realizador como resultado del elogio a un trabajo admirado durante años. Esto, además, conlleva la denostación de la figura del guionista, para muchos autor en la sombra durante la época de los estudios de Hollywood, y que hoy en día goza de una presencia y reconocimiento que en ocasiones le sitúa como autor de una obra cinematográfica, por encima de su realizador -será habitual encontrar eslóganes publicitarios que comiencen con la expresión "del guionista de", obviando el nombre de su director.

La política de los autores llevada a cabo por los críticos de Cahiers tomaba como objeto teórico a los directores de las películas más aclamadas de Hollywood, figuras como John Ford o Jack Conway. Para Maqua, resulta paradójico que los estudiosos franceses fijasen su mirada en una industria en la que el director no era más que otro funcionario al servicio de un gran estudio, y el producto final no era sino un bien

\footnotetext{
1 Truffaut, François, "Une certaine tendance du cinéma français”, Cahiers du Cinéma, Francia n⿳31, enero de 1954, pp. 15-30.
} 
comercial, en lugar de una obra caracterizada por su entidad artística y personal. A pesar de esto, los directores de grandes épicas cinematográficas hollywoodienses se ajustaban a la definición de 'autor' que proponía Cahiers:

Todos los veteranos directores de Hollywood fueron analizados en función de su "puesta en escena"; en sus filmografías respectivas se buscaban afanosamente puntos en común para definir sus "constantes", sus procedimientos habituales de puesta en escena, el toque particular que los distinguía y personalizaba, la "visión del mundo" que los caracterizaba. Se trataba en definitiva, de encontrar la sustancia de un Sujeto Creador, de un Demiurgo Único en la figura del realizador. Le costó mucho al Cine ceder la batuta de la autoría (aunque solo fuera teóricamente) al director, pero era necesario para lograrle un estatus artístico. En el fondo era inconcebible pensar en un autor colectivo, en una obra de arte realizada por muchos a la vez. Ni las viejas catedrales de tan difusa "autoría", ni la ambigua situación autoral del teatro pasaron a impedir que la noción romántica del "autor único y todopoderoso" se impusiera en el arte de hacer películas” (Maqua, 1992:75).

El carácter audiovisual del medio cinematográfico obliga a los estudiosos a ampliar la consideración de que autor es únicamente quien escribe el texto. De esta manera, el realizador, mediante su ejercicio de arquitectura visual, logra la sola autoría -siempre que su identidad quede manifiesta en su manera de dar forma a la historia ante nuestros ojos- por encima del guionista, que es quien aporta el texto original, con sus argumentos y personajes. Esta concepción lleva a los directores a ser considerados “estrellas” a finales de los cincuenta. Según Maqua, el director cinematográfico es considerado por los críticos de Cahiers el "Autor Demiurgo" como resultado de la necesidad de encontrar un "Sujeto Relatador" de las películas, ya que casi todas poseían un carácter de relato (1992:73). De esta manera, el director se convierte en autor porque nos relata la historia, aunque esta esté escrita por otro.

No ocurre lo mismo en el medio televisivo, en el que el director será en la mayoría de ocasiones un empleado al servicio de la creación de un productor ejecutivo -lo que sucedía en la era de los estudios de Hollywood-, y que rara vez aportará su visión personal o dejará en el producto sus estilemas de autor.

La cuestión de la autoría en televisión es un problema complejo, en el que pocos investigadores se han adentrado a fondo. Debido a la extrema fragmentación del medio televisivo, y la habitual rotación en los miembros de un equipo de producción de un programa o serie de televisión, es una tarea complicada asignar la responsabilidad creativa a un solo nombre, como ocurre en el cine. Es por esto que autores como Gérard Imbert aseguran que "la televisión se define por su carácter 
abierto, sin autoría -o de autoría difusa y mediana-, sin límites temáticos” (2008:39), algo que es potenciado por la presencia del propio espectador en los discursos televisivos, "hecho que diluye todavía más la noción de autoría, fenómeno muy representativo de la narración postmoderna" (2008:69). Es, sin embargo, esta una generalización arriesgada, puesto que está cimentada en el estudio de programas que pertenecen al género informativo o reality shows, obviando de esta manera el drama televisivo, uno de los géneros con mayor presencia y repercusión en el medio. Las similitudes del drama televisivo -norteamericano- con el medio cinematográfico especialmente en el terreno estético, y cada vez más, en el narrativo- hacen de las series de televisión que pertenecen a este género un terreno idóneo para aplicar la teoría de los autores, y refutar la idea de una televisión sin autoría. Sin embargo, identificar responsables únicos de una obra será en muchas ocasiones una tarea complicada, e incluso imposible. Barbara Maio opina que no es correcto abordar el problema de la autoría en televisión focalizándolo en la búsqueda de un responsable único del producto: "La questione sembra essere il grado di autorialità che ogni autore riversa nel prodotto poiché la televisione, più che altre espressioni creative, risulta essere una creazione poliautoriale. Ed è utile rilevare che il grado di autorialità presente in un prodotto non dispende esclusivamente dalle menti che partecipano alla creazione ma anche dalla tecnologia o dal mezzo scelto per la creazione autoriale stessa" (2009:33). La dificultad a la hora de atribuir la "paternidad" a un producto televisivo reside en la presencia de múltiples factores, objetivos y subjetivos, que obstaculizan cada intento de ligar un nombre concreto a un único producto televisivo (Maio, 2009:34).

Robert J. Thompson afirma en una de las obras pioneras en el estudio de la autoría en televisión, Prime Time, Prime Movers, que el producto artístico suele ser resultado del esfuerzo de una mente creativa individual (1995:3). Sin embargo, en el caso del drama televisivo, el resultado suele ser un producto del esfuerzo colectivo, lo que conlleva una dificultad añadida a la hora de atribuir la responsabilidad de la creación a un solo nombre.

Volviendo a Maio, la autora habla de una autoría escindida en el medio televisivo, obligada por factores económicos y pragmáticos: El aspecto colaborativo es esencial en una industria como la televisiva, que funciona con importantes restricciones de 
tiempo y presupuesto, y necesita crear productos que puedan extenderse en el tiempo (2009:24).

A partir de la década de los ochenta, comienza a ser habitual ligar los productos televisivos a un único nombre, a un gran productor televisivo que desarrolla una producción dramática con multitud de rasgos en común -a pesar de la fragmentación y la dilatación en el tiempo de los productos. Sería el caso de los ya mencionados Steven Bochco, David E. Kelley o Aaron Spelling. Estos productores ejercen como supervisores de un trabajo colectivo cuyo resultado llevará un sello de identidad que permitirá relacionar su nombre con cada una de sus series. Para Robert J. Thompson, "even in production modes that employ dozens of specialists, individual people [...] must finally take responsibility for making the scores of decisions that determine the character of every moment of a televised drama" (1995:4). Estas decisiones se realizarán teniendo en cuenta factores internos y externos al texto, y trascenderán el ámbito del trabajo en cadena habitual en las series de televisión, para imponer finalmente los elementos de estilo personal de cada uno de estos productores -algo que era habitual durante la era de los estudios de Hollywood.

A pesar de que es posible atribuir nombres propios a muchos productos seriales desde los inicios de la televisión comercial en Estados Unidos en la década de los cincuenta -especialmente en el caso de algunas antologías, como las producidas por Alfred Hitchcock o Rod Serling-, es partir de los noventa cuando la necesidad de que los artistas individuales se responsabilicen de las series televisivas es más acuciante que nunca, debido al empeño de empresas y vendedores en poner etiquetas con nombres propios a todos sus productos, es decir, "designer labels" (Thompson, 1995:4). Por esta razón, el drama televisivo norteamericano ha ido ganando en homogeneidad a la vez que sus propuestas son cada vez más variadas y originales. Las cadenas ofrecen a la audiencia la familiaridad que conlleva un nombre conocido junto a una nueva propuesta. De esta manera, el espectador se acercará al producto de acuerdo a una expectativas, sin importar en muchos casos el género al que se adscriba la serie. Ya en la postelevisión, esta tendencia forma parte integral de las nuevas estrategias retóricas del medio.

\section{La pugna por la autoría en televisión}


A pesar de que ya hemos observado cómo es habitual adjudicar la autoría de las series dramáticas de televisión a la figura del productor ejecutivo, es necesario detenerse en las razones por las que esto es así, además de en otras figuras importantes del proceso creativo de una serie de televisión, para observar que es posible -aunque no habitualdesplazar la autoría televisiva a otros miembros del equipo.

\subsection{El productor ejecutivo y el show-runner}

Ya hemos visto que según la política de los autores de Cahiers du Cinéma, el autor es el realizador, quien pone en escena. Ahora bien, en televisión, esta noción del director como autor pierde validez, puesto que el director será en muchos casos tan solo un miembro más del equipo que debe encargarse de hacer llegar al espectador una visión unificada y homogénea que responda a la imagen de un autor, en este caso, el productor ejecutivo o creador de la serie. Según Steven Priggé, el éxito de una serie de televisión recae completamente sobre el creador del programa, ya que los actores, actrices y directores siguen el guión e interpretan -en lugar de crear. A pesar de que el creador de una serie de televisión siempre cuenta con un equipo de guionistas que se encargan de prolongar sus ideas y conceptos, la consistencia temática de la serie desarrollada a través del argumento, la caracterización y el diálogo- está en manos del creador (2005:1).

Es por tanto necesario en primer lugar establecer las diferencias entre el productor y el creador de una serie. Si es que, como veremos, estas existen. Será más que habitual que el creador de una serie de televisión sea a su vez el productor ejecutivo, cuyo rol será llevar a cabo las relaciones con la cadena y supervisar todos los aspectos del proceso creativo de la serie. "El papel del productor en la televisión norteamericana ha estado ligado históricamente a las relaciones que se han establecido entre las cadenas y los proveedores de programas, así como a la evolución del propio sistema de producción y programación" (Villagrasa, 1989:98). Es el productor quien se encarga tradicionalmente de levantar los cimientos de un programa, y el que, en muchas ocasiones, presentará la idea original de una serie a la cadena. No obstante, "en muchos casos, la figura del productor ejecutivo no coincide [...] con la del creador, pero, en última instancia, acaba moldeando la serie" (Villagrasa, 1989:104). 
Es posible además que el creador de una serie sea un actor cuya popularidad le permita vender su propuesta a la cadena, y más habitual aún que se trate de un guionista que presenta a la cadena el germen de una serie, a través del guión para un piloto. Por lo tanto, la figura del creador trascenderá cualquier título corporativo para situarse en un espacio prácticamente aislado del proceso de producción de una serie. Es decir, cualquiera puede crear una serie, siguiendo el proceso habitual de presentación de la propuesta a la cadena -lo que se conoce habitualmente como pitch.

Desde finales de los cincuenta, podemos observar cómo guionistas experimentados y aclamados como Rod Serling se convertían en productores ejecutivos de nuevas series, pasando así a tomar las riendas del control creativo. Tradicionalmente, las figuras del productor ejecutivo, el guionista y el director estaban mucho más diferenciadas dentro del medio televisivo. El productor no asumía labores de guión o dirección, sino que se encargaba únicamente de las tareas corporativas, el director era tan solo un contratado - a pesar de que de los primeros dramas televisivos surgieran grandes directores cinematográficos, como Sidney Lumet- y el guionista no era más que un artesano al servicio del productor ejecutivo y de la cadena. Serling es el antecedente de los grandes productores ejecutivos que a partir de los setenta comenzarán a labrarse un nombre en la industria televisiva, no solo generando grandes éxitos gracias a sus dotes de relación con las networks, sino también a su labor como guionistas -que desempeñaron durante años antes de pasarse a la producción. Sería el caso por ejemplo de Jack Webb -Dragnet- o Quinn Martin -El fugitivo, El F.B.I.- en la década de los setenta o Steven Bochco, y con una menor repercusión en el medio, Marshall Herskovitz y Edward Zwick en los ochenta.

A finales de los ochenta, la industria televisiva presenta tres categorías de productores, como resultado de las migraciones de los profesionales de una tarea a otra:

- El productor independiente: un profesional que recibe directamente el encargo de la cadena para realizar proyectos (Steven Bochco);

- La compañía de producción: un productor-guionista o un actor, deciden montar su propia firma para llevar adelante varios proyectos no creados únicamente por él mismo (la productora MTM, Aaron Spelling o Stephen Cannell); 
- El productor de estudio: bajo el auspicio de las majors se amparan en creadores y guionistas que se encargan de llevar adelante los proyectos (Villagrasa, 1989:101).

Barbara Maio, por su parte, identifica dos tipos de productor-autor televisivo: por una parte, el que trabaja en cine y televisión simultáneamente, o bien proviene del cine y ocasionalmente hace incursiones en televisión -David Lynch, Steven Spielberg, James Cameron, Walter Hill, Francis Ford Coppola- y por otra, el que nace en el medio televisivo y ocasionalmente trabaja para el cine -Aaron Spelling, Chris Carter, Joss Whedon, Steven Bochco, David Chase. A pesar de que para Maio no basta con un nombre conocido para asegurar el éxito o la calidad de una serie, es habitual identificar estilemas de autor en las obras televisivas de cineastas, lo que demuestra que desde la producción ejecutiva será posible imprimir un sello personal en una serie televisiva, como ocurre por ejemplo en el caso de Steven Spielberg, cuya película Encuentros en la tercera fase (Close Encounters of the Third Kind, 1977) compartirá elementos temáticos y estéticos con su serie Abducidos (Taken, 2002) (2009:29).

James L. Longworth Jr. (2002) destaca además cómo a finales de la década de los noventa es habitual que los grandes profesionales del cine se conviertan en productores de televisión e impriman su sello personal en series dramáticas de éxito. Los grandes cambios en los conglomerados multimedia norteamericanos a finales de los noventa acercan ambos medios mediante una integración vertical. La ABC y Lifetime son adquiridas por Disney y CBS es comprada por Viacom. En 2001, la fusión de America On Line (AOL) y Time Warner Cable unía a HBO y la Warner Brothers Television, que desarrollarían series dramáticas para CBS y NBC (Longworth Jr., 2002).

La "nueva era del drama" en televisión invita a directores y productores cinematográficos de renombre a sumergirse en la producción televisiva. Según Longworth Jr., Showtime y HBO son las responsables de este fenómeno. Ambas cadenas de pago habían conseguido el éxito gracias a películas de producción propia para televisión, pero fue a partir del éxito de Los Soprano cuando los profesionales del cine se fijaron en el potencial narrativo del formato serial, contribuyendo así a un cambio en las dinámicas de la industria audiovisual norteamericana (Longworth Jr., 2002:XXI): a partir del comienzo del nuevo milenio, lo habitual será que se dé el salto de la gran a la pequeña pantalla, y no al contrario, que era lo que venía sucediendo Admira $n^{\circ} 3-2011$ 
hasta el momento. Los actores de Hollywood encontrarán asimismo en la televisión el refugio perfecto para continuar sus carreras, con la posibilidad de prestigio y reconocimiento crítico que el medio no ofrecía anteriormente. El autor explica este cambio de la siguiente manera:

\begin{abstract}
Once again, $\mathrm{HBO}$, which also had $\mathrm{Oz}$ in its stable, was raising the bar for dramatic television, causing everyone else to develop more innovative hour shows. To better compete in the drama genre, networks and cable even reached out to men who had made their reputation in big-screen motion pictures. Joining TV veterans Ed Zwick, Marshall Herskovitz and Barry Levinson (thirtysomething, Once and Again, Homicide: Life on the Street) were more big names, including James Cameron (Fox's Dark Angel), Paul Attanasio (ABC's Gideon's Crossing) and Sidney Lumet (A\&E's 100 Centre Street), all of whom crossed over into TV in the new millenium. Clearly, the once-mighty barriers between the two industries of film and television had come tumbling down, and TV was much the richer for it (2002:XXI).
\end{abstract}

Esta tendencia iría al alza a lo largo de la primera década del siglo XXI, durante la cual el número de renombrados directores, productores y guionistas de Hollywood que se convertirán en productores ejecutivos y creadores de series aumentará enormemente: Jerry Bruckheimer -que ya tenía experiencia previa en televisión- con Sin rastro o la enormemente popular CSI y todos sus spin-offs; James Cameron (Dark Angel); Bryan Singer (House); Steven Spielberg (Hermanos de sangre, United States of Tara, The Pacific), quien había comenzado una relación fructífera con la televisión años antes; Alan Ball ( $A$ dos metros bajo tierra, True Blood); Ridley y Tony Scott (Numb3rs, Los pilares de la Tierra); Doug Liman (The O.C., Covert Affairs); McG (The O.C., Sobrenatural); Brett Ratner (Prison Break).

Martin Scorsese es uno de los últimos directores de renombre en aventurarse como productor ejecutivo de una serie de televisión, con la aclamada Boardwalk Empire (2010-), de HBO. Como Scorsese, un gran número de realizadores cinematográficos ha decidido implementar su carrera en el cine con la experiencia catódica: Frank Darabont ha creado la exitosa serie The Walking Dead (2010-) para la cadena AMC, George Clooney ha ejercido de productor ejecutivo de Memphis Beat (2010-2011) para TNT, Neil Jordan produce Los Borgia (The Borgias, 2011-) para Showtime y Michael Mann y David Fincher preparan sendos proyectos para su estreno en 2012 en HBO, Luck y House of Cards, respectivamente.

Como ya hemos visto, también será habitual que directores de renombre asuman las labores de realización de episodios de series producidas por otros -Jonathan Demme dirige el episodio piloto de la serie de HBO The Long Fall. Es el caso de Tarantino Admira $\mathrm{n}^{\mathrm{o}} 3-2011$ 
para CSI y más recientemente Bill Condon, que se encargó del piloto de la dramedy The Big C, para Showtime. El realizador argentino Juan José Campanella ha dirigido un gran número de episodios de algunas series de éxito, como House o Ley y orden: Unidad de víctimas especiales -además de crear, producir y dirigir la co-producción hispano-argentina Vientos de agua. El grado de presencia de cada director en el estilo y contenido de la serie variará según el caso. Tarantino imprimirá su sello inconfundible en $C S I$, mientras que Campanella adoptará el estilo y el tono marcado desde el comienzo de las series en las que trabaja.

Volviendo a la figura del creador televisivo, sin la necesidad de identificarlo como productor o guionista, será su nombre el que permanecerá en los créditos durante toda la duración de la serie. No obstante, este puede permanecer involucrado realmente en la producción de la serie - produciéndola o escribiendo los guiones- o marcharse a realizar otros proyectos, dejando tan solo su nombre, que en muchos casos conllevará unas señas de identidad y una creación de expectativas para la audiencia, como ya hemos visto. Será en las series que cuentan con la presencia real de su creador como miembro activo del equipo en las que la idea del creador/productor ejecutivo como autor será más justificable.

“There is no questioning the magnitude of a show's initial and ongoing contribution. In his or her head alone is the ultimate blueprint responsible for a show's overall impact on an audience" (Priggé, 2005:1). El creador de una serie dispone las ideas principales, el tono, los personajes y las líneas argumentales creando así, como sugiere Priggé, unas líneas maestras que el equipo de guionistas debe seguir. Los productores ejecutivos de las series de televisión contratan a guionistas que sean capaces de seguir su visión, produciéndose de esta manera una suerte de extensión de la autoría original. Esto se debe a que, por regla general, los guionistas serán contratados de acuerdo a su capacidad de ajustamiento a la visión original, y serán sustituidos por otros en el caso de no alcanzar las expectativas. El productor de televisión Joss Whedon se refiere al creador televisivo como a un mentor. Según su experiencia, el productor está constantemente inmerso en la búsqueda de nuevos talentos que no solo se ajusten a la visión original de la serie, sino que sean capaces de aportar nuevas ideas (2005). La búsqueda de talento lleva al productor a despedir y contratar a nuevos guionistas hasta dar con el equipo perfecto, un equipo sólido de 
guionistas que, como ocurre en el caso de Whedon, le acompañará en muchos de sus proyectos.

Barbara Maio coincide con algunos de los autores citados en que la figura del productor televisivo es la más importante e influyente dentro del proceso de creación de una serie. A pesar de esto, el resultado final siempre será obra de un esfuerzo colectivo. Para Maio, es posible aplicar la teoría baziniana de la autoría a la televisión (2009:24). Solo basta con buscar los rasgos personales de un mismo sujeto individual en varias de las obras de las que es responsable. Puesto que un realizador de televisión trabajará como contratado en varios programas, es la figura del productor ejecutivo o creador la que se prestará más fácilmente a esa homogeneización de características personales con el fin de crear un perfil autoral. Villagrasa sugiere a finales de los ochenta un modelo de productor ejecutivo-autor que triunfa en la televisión norteamericana y cuyas características nos sirven para describir a la figura del autor de drama televisivo durante la postelevisión:

El productor, y más concretamente el productor ejecutivo, ha adquirido notable relevancia entre los círculos de la crítica y de las publicaciones especializadas. Su figura se ha convertido en una especie de padre del programa, autor escondido y omnipresente que imprime su huella en los trabajos que factura para el gran consumo en las ondas. El productor ejecutivo aúna tres tareas: la de crear el espacio y controlar su evolución narrativa durante la vida de emisión, la de mantener la relación con la cadena y la de estructurar un sistema de producción adecuado para las necesidades económicas de la productora (1989:101).

Aaron Spelling, Glenn Gordon Caron, David E. Kelley, Glenn Larson, Steven Bochco o Susan Harris "son algunos de los nombres que pueblan la cúspide creativa de la industria. Todos ellos se han especializado en un género, en una tipología de personajes, o han abierto tendencias narrativas irrefutables" (Villagrasa, 1989:101). Esta descripción del productor ejecutivo se ajusta a figuras de la postelevisión como Joss Whedon, David Simon, Aaron Sorkin o Alan Ball, con una única diferencia: en ninguno de los casos, se tratará de un "autor escondido", en tanto en cuanto su responsabilidad como creador y su labor en el desarrollo de la serie se hará visible y explícita constantemente.

Todos estos productores ejecutivos logran trascender el trabajo en equipo que conlleva cada uno de sus proyectos, cultivando una imagen de autor a base de rasgos estilísticos y de repetición de temas que permitirán trazar una personalidad artística muy definida. Durante las dos últimas décadas, el productor ejecutivo es consciente Admira $\mathrm{n}^{\circ} 3-2011$ 
de la repercusión que puede tener su trabajo en televisión en oposición a las décadas anteriores. Esta auto consciencia potencia la repetición de elementos personales, con la intención de obtener el reconocimiento como autor. Aaron Sorkin, experimentado guionista cinematográfico, se caracteriza por abordar temas polémicos como la política -habitualmente ignorada en el drama televisivo norteamericano-, y lo hace con un estilo propio muy identificable, a través del uso del diálogo que ocupa prácticamente la totalidad del episodio y marca el ritmo, define la acción y aporta la estructura narrativa. Este estilo personal subyace de cada una de sus series, permitiendo de esta manera identificar la serie como el trabajo de un solo autor. "And no matter what accolades Martin Sheen or Allison Janney receive for their work on The West Wing, Aaron Sorkin is always prominently featured in discussions of the show. We don't think about the team of writers behind Sports Night or the staff generating story ideas for The West Wing, we think only of Sorkin. Wether intentionally or not, Sorkin has made himself and his image an integral part of his work" (Fahy, 2005:2).

Por otra parte, Alan Ball, reputado guionista de cine, como Sorkin, trasladó los rasgos más reconocibles de su obra cinematográfica a la serie $A$ dos metros bajo tierra, dirigida por Sam Mendes: realismo y contemplación opuestos a ocasionales momentos de surrealismo, una alta hibridación genérica, crítica a la doble moral de la sociedad norteamericana, guiones basados en la evolución psicológica de los personajes, en lugar de la acción.

Sin embargo, los nombres de J.J. Abrams y Joss Whedon son quizás los que han sonado con más fuerza desde finales de los noventa, gracias a su condición de "autores de culto". Este título, otorgado por las audiencias tras el éxito de series de género fantástico y acción -ambos géneros adscribibles a la categoría de drama televisivo norteamericano- les ha convertido en referentes ineludibles del drama de calidad en televisión. El primero ha encontrado un hueco privilegiado en el gremio de directores y guionistas de Hollywood gracias a su labor en series de repercusión internacional como Alias, y sobre todo, el fenómeno Perdidos. Las obras de Abrams se caracterizan por unos intrincados guiones repletos de giros argumentales y golpes de efecto, una gran dependencia del cliffhanger, que convierte sus obras en masivos arcos argumentales, y una experimentación narrativa -con el flash-back y el flash- 
forward como recurso básico- que ha influido en todo el drama televisivo desde 2004. Sin embargo, el hecho de que Abrams ejerza de productor ejecutivo para muchas series y después las abandone delegando en otros productores para poder iniciar nuevos proyectos, pone en duda su categoría como autor. Abrams se ha convertido más bien en una 'marca registrada', un elemento importante en las estrategias de márketing de las cadenas, interesadas en poner nombre propio a sus productos, sin importar si estos responden realmente a la imagen desarrollada por el autor. Seis grados de separación o la reciente Undercovers son ejemplos de series de Abrams en las que el nombre del productor se convierte en 'logo'.

Por su parte, Joss Whedon es el autor de culto por excelencia de la televisión norteamericana, gracias en gran medida a la repercusión de su obra Buffy, cazavampiros tanto en la audiencia como en la crítica especializada y el ámbito de la investigación. Las obras de Whedon se caracterizan por unos diálogos repletos de referencias a la cultura popular, una creativa manera de utilizar el lenguaje, ${ }^{2}$ una alta autorreflexividad, un intrincado y arriesgado desarrollo de personajes, el uso de las metáforas fantásticas para explicar procesos psicológicos del ser humano, y la recurrencia de temas como el poder y corrupción, el paso de la adolescencia a la vida adulta, la adicción o la familia. Por otra parte, la participación repetida de un gran número de actores en sus proyectos -los llamados Whedon Alumni Nathan Fillion, Summer Glau, Felicia Day, Eliza Dushku, Amy Acker, Alexis Denisof, Alan Tudykcontribuirá al reconocimiento inmediato de una serie como obra de Joss Whedon.

Antes que Sorkin, Ball, Abrams o Whedon, otros productores televisivos han logrado imprimir su sello personal en todos los proyectos que han llevado a cabo, a pesar de no estar involucrados en los procesos creativos de sus series, más allá del planteamiento inicial. Aaron Spelling fue uno de los productores más prolíficos del medio, generando éxitos y desarrollando un estilo propio que se repetirá en todas sus producciones. Según Cascajosa Virino, "Spelling ha estado produciendo éxitos desde finales de los cincuenta, gracias a que se centró en poner los elementos básicos para el

\footnotetext{
${ }^{2}$ La publicación Slayer Slang: A Buffy the vampire Slayer Lexicon (Michael Adams, 2004) recoge un completo léxico a partir de las novedosas expresiones y formas gramaticales que los guionistas de la serie crearon y sus personajes popularizaron a lo largo de sus siete temporadas.
} 
desarrollo de los programas, desde el planteamiento argumental hasta el equipo creativo, en vez de llevar el día a día de cada uno de ellos. Sus series también iban a tener características comunes, entre ellas una iluminación cara, lujosos ambientes y gusto por los cuerpos bellos" (2005:29). Pero sin duda es Steven Bochco uno de los productores más aclamados y reconocidos, gracias a la repercusión en el medio de su serie Canción triste de Hill Street, que cambiaría para siempre el panorama del drama televisivo en Estados Unidos, mediante una serie de revolucionarias novedades narrativas que definirían su estilo e influirían a toda la producción dramática posterior. Canción triste de Hill Street

\begin{abstract}
supuso un hito en la evolución estética de las series televisivas. La historia de la comisaría de Hill Street propuesta por Bochco y Kozoll desplegaba un número inusual de protagonistas centrales, entretejía innumerables historias en cada episodio, explotaba la tendencia $[\ldots]$ al policentrismo y a la creciente concentración temporal, hacía de la fragmentación una figura de estilo, diseñaba una peculiar manera de articular el tiempo de cada microrrelato con el general de la serie, ofrecía una visión del melting pot americano, construía un peculiar lugar para el espectador y [...] edificaba una apariencia perceptiva en torno a determinadas codificaciones del realismo que la apartaban decisivamente del universo tradicional de las soap operas (Zunzunegui, 1989:138).
\end{abstract}

En los últimos años, el término show-runner ha cobrado una gran relevancia en la producción de series televisivas en Estados Unidos, especialmente en las de género dramático. Jason Brett se define a sí mismo como show-runner: "I am what is referred in my industry as writer-producer and show-runner. That means I can create my own shows and run the series once they go into production. When I write a pilot script I'm paid by a production company which is reimbursed by a network" (1994:25).

Las diferencias entre el productor ejecutivo de una serie y su show-runner no son fáciles de establecer, principalmente porque desempeñarán las mismas funciones y en muchos casos, ambos títulos pertenecerán a la misma persona -como hemos visto con el caso de Brett. Es más, se podría decir que se trata solo de dos formas de referirse al mismo puesto en una producción televisiva. La principal diferencia entre ambos siempre que productor ejecutivo y show-runner no sean la misma persona- se encuentra en el grado de implicación de cada uno con el desarrollo creativo de la serie. Mientras el productor ejecutivo hará de enlace con la cadena y supervisará la producción global de la serie, el show-runner se ocupará del desarrollo y supervisión de los guiones y de la producción de cada episodio -además de tomar decisiones con respecto al reparto, la selección de miembros del equipo o el devenir argumental de 
una serie. Es decir, el show-runner es el encargado del día a día en la producción de una serie, mientras que el productor ejecutivo, a pesar de mantener sus labores de supervisión, podrá comprometerse con otros proyectos. El grado de compromiso del show-runner será por tanto mayor, debido a su presencia en el proceso de producción de cada episodio. Sin embargo, debido a que la tarea desempeñada por ambos es similar -variando solo el grado de presencia capítulo a capítulo- el show-runner aparecerá en los créditos de la serie como 'productor ejecutivo' -aún no es habitual que el término show-runner aparezca como una entrada independiente a la de productor ejecutivo. Normalmente, el show-runner se encargará además de los guiones, siendo en definitiva la figura que controle todos los aspectos creativos de una serie. Jason Brett ofrece las claves que nos ayudarán a comprender cuáles son exactamente las funciones del show-runner y por qué esta figura es esencial para el desarrollo de las series de larga duración:

\begin{abstract}
For a show to become a successful long-running television series, every aspect of the production machinery has to work at peak performance to crank out shows that meet the same exact standards week after week after week. This is where the writerproducer makes the transition into something we call a showrunner. [...] It takes a combination of creative talent, and sheer nuts-and-bolts experience, and it starts with vision - the ability to project a show into its future, to know how to evolve it and where to take each individual character and how to keep the audience interested and committed. A show-runner arcs a season's worth of shows like a writer structures a script (1994:32-33).
\end{abstract}

Por tanto, el uso del término show-runner en los últimos años se debe en parte a la necesidad de tomar en consideración la figura del nuevo modelo de productor ejecutivo en la televisión norteamericana, alguien que además de desempeñar labores corporativas, se comprometerá con el desarrollo argumental y todos los aspectos artísticos de la serie -en definitiva, alguien que pugnará con el creador por la autoría de la serie. Tomemos el caso de la ya mencionada serie de ABC Perdidos, para ilustrar las posibles diferencias entre productor ejecutivo y show-runner. J.J. Abrams desarrolló junto a Jeffrey Lieber y Damon Lindelof la idea y las principales líneas argumentales de Perdidos. Los tres productores y guionistas aparecerán en los créditos de la serie como creadores y productores ejecutivos. Sin embargo, Abrams se desligará -relativamente- del proyecto para producir otras series y delegará en Damon Lindelof y Carlton Cuse -guionista de la serie-, que se convertirán en los showrunners de Perdidos hasta su final en 2010. De este modo, Abrams seguirá ostentando su título como creador y productor ejecutivo de la serie, asegurándose así que 
Perdidos siempre esté relacionada con él, a pesar de que serán Lindelof y Cuse los que tomarán las riendas y controlarán todos los aspectos económicos y creativos de la serie. Es ya habitual que el show-runner de una serie de televisión sea además guionista y dirija muchos de sus episodios, como es el caso de Lindelof y Cuse. Se trata, como adelantábamos, del nuevo productor ejecutivo que asumirá la responsabilidad absoluta del proyecto y competirá con el creador por el título de autor.

Es curioso sin embargo que, a pesar de delegar en Lindelof y Cuse, Abrams será a menudo identificado como el único responsable -o representante- de Perdidos. Esto no hace sino confirmar la importancia de la figura del creador de una serie y la huella imborrable que deja su nombre durante lo que dura su emisión. A pesar de que Lindelof y Cuse tomaran las riendas del proyecto en cuanto Abrams se marchó a producir Seis grados de separación o Fringe, lo más habitual será referirse a Perdidos como "una serie de J.J. Abrams" y no "una serie de Damond Lindelof y Carlton Cuse". La labor como guionistas de Lindelof y Cuse queda por tanto relegada a la sombra, como ocurrirá en un gran porcentaje de series norteamericanas, a menos que el nombre del creador coincida con el del guionista.

\subsection{El guionista y el director}

La labor del guionista de una serie de televisión es quizás la más exigente y, en proporción al volumen de trabajo requerido, la menos valorada dentro de la industria televisiva. Sin embargo, en los últimos años, el guionista televisivo ha adquirido una importancia y un reconocimiento que no tenía antes en la industria, y que se opone al que posee el guionista cinematográfico. Según el productor J.J. Abrams,

\footnotetext{
the writer on a film is not regarded the same way as a writer on a television show, because once the film is being made, they don't really need the writer anymore. Television is this ongoing process where the writer is genuinely needed. It is this Darwinian thing where the requirement is that we need ongoing scripts in order to make the show happen. So, there is an awareness of the value of writers, which, unfortunately, is largely absent on feature films (Priggé, 2005:165).
}

La clave del éxito prolongado de una serie de televisión reside en sus guiones y en el desarrollo de sus personajes, especialmente dentro del género dramático, puesto que en la telecomedia será más habitual que los personajes no cambien apenas durante 
toda la serie y sean las situaciones, y especialmente los chistes y gags, lo que mantenga la fidelidad del espectador. De la misma manera que la familiaridad con un género crea expectativas, los guiones de las series de larga duración tratan de sacar el máximo partido a los personajes que el espectador conoce perfectamente, para garantizar la fidelidad y a la vez sorprender y mantener el interés. Es fácil para el espectador adentrarse en una serie si conoce de antemano su estructura y sus formas, y la responsabilidad de mantener estos elementos fieles a la naturaleza del producto reside en la figura del guionista. Como indica Cascajosa Virino,

\begin{abstract}
desde el punto de vista de la producción existen unos sistemas de reglas y convenciones previamente establecidas, un conjunto de procedimientos repetidos para construir los discursos, unas normas de coherencia textual que sirven de modelo convencional para elaborar discursos adscritos a un género determinado. La repetición, los tópicos de contenido, los lugares comunes o las convenciones formales son cuestiones relacionadas con el género y la autoría. No se trata sin embargo de un sistema de características completamente cerrado, sino que las aportaciones personales de los diversos autores permiten que el género evolucione y se mantenga vivo durante mucho tiempo (2005:104).
\end{abstract}

Debido a la inmediatez de la producción televisiva y a los consiguientes plazos acelerados para entregar episodios finalizados a las cadenas, el trabajo de guión no puede recaer, en la mayoría de los casos, en una sola persona. Por esta razón, prácticamente todas las series de larga duración contarán con un equipo de guionistas, siendo imprescindible en el caso de la sitcom, para la que el brainstorming en búsqueda del gag perfecto es esencial. La evolución que experimenta el género dramático en la televisión norteamericana durante los ochenta potencia esta necesidad de aumentar el número de guionistas para cada episodio. Jeffrey Lewis aporta las dos razones principales por las que esto ocurre: cuestiones de desarrollo de tramas y personajes - es complicado escribir un guión de sesenta páginas todas las semanas- y cuestiones económicas -el Writers Guild of America, gremio de los guionistas norteamericanos, pagaba lo mismo a un guionista que había escrito la mitad de un episodio que a uno que había escrito un cuarto (1994:61). La complicación en las tramas de Canción triste de Hill Street y el aumento del número de personajes obliga al drama de Steven Bochco a ser uno de los primeros en contar con equipo de guionistas.

Para Lewis, sin embargo, la escritura de guión en grupo conlleva sacrificar la autoría de los guionistas, puesto que tradicionalmente se reserva a uno o dos nombres: "This process encourages a sense of craftmanship, which is useful, as opposed to Admira $\mathrm{n}^{\mathrm{o}} 3-2011$ 
authorship, as opposed to the feeling that writers have of "us against the world", which can lead to alarmingly grotesque versions of that world, as well as genius versions. Here one thinks the project is outside oneself a little more, like hammering away at a sculpture on a cathedral rather than doing the whole thing" (1994:68). Para John Wells, "the writing process in America is not viewed in what has come to be known as film-auteur terms. [...] you can become very attached to what you're writing and really relieve in it, but you're going to be required to be involved in so many other things at the same time, that it doesn't become a singular obsession" (1994:99).

Aunque esta labor tenía varios aspectos positivos. En primer lugar, los guionistas adquirían un poder sobre el proyecto del que no disfrutaban anteriormente, y en segundo lugar, lograban canalizar sus visiones personales dentro de un esfuerzo colectivo sin que el resultado final perdiera coherencia:

There were also some unexpected benefits of writing this way. One is that it was possible to get a degree of universality into the project without losing a certain degree of particularity. [...] It's very hard to write an intensely private story when there are so many people in the room, when there are so many eyes on the project. One tends to become part of the communal effort and get outside oneself more than otherwise, so the themes and outlooks tend to become a little more widely held by necessity in order to accommodate the various voices and talents and consciousnesses in the room. At the same time, dividing the work and redividing the work and ultimately leaving one person the opportunity of doing this or doing that, one doesn't necessarily lose the particularity that only one writer can bring to one scene (Lewis, 1994:67-68).

No obstante, será habitual que una persona se encargue de supervisar y corregir el resultado final, generalmente un guionista más experimentado o uno de los productores ejecutivos o creadores de la serie. Es lo que muchos llaman un "doctor de guiones", figura que se encarga de supervisar, corregir guiones de otros guionistas sin interferir en los argumentos desarrollados y mantener la coherencia del relato a lo largo del tiempo -Michael Kozoll es uno de los doctores de guiones más importantes, por su trabajo en Canción triste de Hill Street.

“Aunque por su propia naturaleza, la televisión es un medio irregular, cuando una serie cuenta con un productor principal de talento que logra reunir a un buen equipo de trabajo, este sistema permite un relato centrado más en las necesidades de la historia que de otro tipo de factores, incluso la puntual interferencia de la cadena de televisión" (Cascajosa Virino, 2005:9). La figura descrita por la autora coincidirá a menudo con la del show-runner. Como explica Lewis, "regardless of how big the Admira $n^{\circ} 3-2011$ 
show's writing staff might be, most show-runners take the final pass on each and every script to make sure each show has a singular voice" (1994:33).

Douglas Heil (2002) considera que en la formación de los guionistas para su trabajo en la televisión se tiende a obviar la noción de la autoría. En su lugar, se analizan y transmiten estructuras narrativas convencionales o formatos profesionales que el guionista aprendiz asumirá antes de comenzar a escribir. De esta manera, es complicado desarrollar un estilo individual y un punto de vista personal. Para Heil, esto resulta en la imitación formulaica, lo que conduce a la devaluación del guionista dentro de la industria televisiva, convirtiéndolo de esta manera en una figura intercambiable. En consecuencia, "when authorship is perceived in episodic television, it is attributed to the creator/producer and not to the writer" (2002:XIV).

Los guionistas de televisión -especialmente los de género dramático- trabajan de la misma manera que los directores en la era de los estudios de Hollywood -son contratados para aportar su visión a un proyecto que no nace de sus mentes creativas individuales, pero tienen la oportunidad de aportar sus sellos personales. Para Heil, "if auterism can center on Hollywood studio directors and inspire compelling work in contemporary filmmaking, perhaps applying it to television writing can yield similar results. [...] Certain creator/producers who also write, such as Norman Lear, Steven Bochco, and Linda Bloodworth-Thomason, are already perceived to be television auteurs. [...] Freelance and staff writers can also be auteurs" (2002:XV). Por tanto, será el creador/productor que además ejerce como guionista el que más oportunidades tendrá de ser percibido como autor.

En las primeras décadas del medio televisivo en Norteamérica, un número de guionistas destacaron por encima de las cadenas para las que trabajaron, gracias al desarrollo de una personalidad propia y un estilo que supieron imprimir en todos sus proyectos. Es el trabajo de tres guionistas norteamericanos de drama el que permitirá aplicar la teoría de los autores a la televisión, demostrando que a pesar de la enorme influencia y poder de las corporaciones sobre los productos televisivos, las visiones individuales, e incluso autobiográficas, de un grupo de productores lograron encontrar su hueco en el medio: Paddy Chayefsky, Reginald Rose y Rod Serling. 
En las primeras décadas de la televisión comercial norteamericana, la audiencia identificaba las series en relación a la cadena de televisión que las emitía - ABC, NBC o CBS- y no fue hasta los setenta, década en la que los estudios sobre televisión empiezan a despuntar en Estados Unidos y Gran Bretaña, cuando se comienza a estudiar estos primeros trabajos dramáticos como obras de autor. Chayefsky, Rose y Serling son entonces considerados autores en un medio que tradicionalmente excluía a los guionistas y directores de este reconocimiento. David Marc y Robert J. Thompson enumeran las características del estilo de Chayefsky, reconocibles en todos sus guiones, como el popular episodio de la antología dramática Goodyear TV Playhouse, "Marty":

His protagonists were usually middle-class men working in skilled manual professions (butchers and printers, to name two prominent examples). The dialogue spoken by these characters -and the problems they faced -were emphatically common and personal: loneliness, alienation, social pressure to conform. The technical requirements of live broadcast were a good fit with Chayefsky's drama gestalt: cramped up urban living rooms, small working-class bars, and location shots were strictly out of the question (122).

Reginald Rose no logró tanta atención como Chayefsky, pero consiguió imprimir sus señas de identidad en las antologías para las que escribió guiones, como "Twelve Angry Men", para Studio One, convertida posteriormente en largometraje, al igual que "Marty". Rose se caracterizaba principalmente por el compromiso social y político del que hacían gala sus guiones, abordando temas como los derechos civiles y el racismo. Por último, Rod Serling es uno de los guionistas más aclamados por el público y la crítica a lo largo de la historia del medio, lo que le confiere un estatus de autor de culto que serviría de precedente de guionistas en la postelevisión como Chris Carter (Expediente X). Con la popular En los límites de la realidad, Serling desarrolló en los sesenta una estética personal muy reconocible -e imitada posteriormente por otros programas de formato antológico- aprovechando las posibilidades del género de ciencia ficción.

The leitmotifs that dominate The Twilight Zone are the same ones that Serling had always been associated with: the thin line between ambition and hubris; the price of succes [...]; and the fading lives of fading celebrities, sport heroes, and movie stars. Policitally liberal, emotionally romantic, and philosophically quasi-existential at times, The Twilight Zone was an ideal prime-time vehicle, attracting children with an overflow of macabre glitz and their parents with a surfeit of "heavy" message (Marc y Thompson, 1995:128). 
Para tener una visión más completa del proceso que conlleva la escritura de una serie de televisión de larga duración, el concepto de writer's room es esencial. Contar con un equipo de guionistas es cada vez más habitual en el drama televisivo. Sin embargo, la idea de este equipo reunido en una sala en la que se desarrolla un guión a viva voz y a base de intervenciones -aprobadas o rechazadas instantáneamente- de los guionistas es más propio de la telecomedia. El drama ofrece más oportunidades para escribir de manera más personal e individual, para escribir y desarrollar personajes más complejos desde un punto de vista más psicológico e introspectivo. Esta será una de las razones por las que el drama televisivo será considerado el más cercano formal y temáticamente al cine.

Amy Sherman-Palladino explica por qué un writing staff muy grande puede interferir con la esencia de la serie y con la visión personal de su creador. Para la creadora de Las chicas Gilmore y su marido y co-productor y guionista de la serie, Daniel Palladino, son los mejores autores de televisión los que menos guionistas tienen bajo su supervisión, es decir, los que consiguen mantener su visión y su presencia a lo largo de toda la serie: "You have to protect your ideas and your writing from those outside people with opinions. All of that can dilute the product and weaken it. David Chase does not have 20 people telling him what to do on The Sopranos. [...] When you don't have a hundred people telling you what to do, it gives you a chance to do something good. [...] that's a key ingredient to keeping a show around for a long time" (2005:147).

Sin embargo, esta visión territorialista de la creación propia no es compartida por todos los productores televisivos. Desde su primer trabajo en televisión, Buffy, cazavampiros, Joss Whedon ha confiado sus ideas y su visión a un equipo de guionistas para los que ha servido como mentor, y en los que ha confiado no solo para hacer perdurar su visión original, sino también para aportar nuevas ideas que el productor aprovecharía como punto de partida para muchos episodios. Por su parte, Ilene Chaiken, productora ejecutiva de la serie $L$, considera que el proceso que se lleva a cabo en la writer's room es esencial para el correcto desarrollo de una serie a lo largo de sus temporadas. Chaiken, cuya experiencia previa en televisión incluye varias sitcoms, trató de reunir a un grupo de guionistas cuyas voces pudieran coincidir con la suya, y a la vez fueran capaces de aportar algo único e individual a la serie. 
Según palabras de la propia Chaiken, "the ideas get so much better and they go so many places that you never could have imagined on your own. It is never about one person. It is about the group process. It is about the way we react and interact with one another" (2005:143). Alan Ball, creador de la ya mencionada A dos metros bajo tierra y otra serie para HBO, True Blood, confía su visión a otros guionistas -que trabajan individualmente- y les brinda la oportunidad de tomar absolutamente las riendas de la historia.

Si tuviéramos que realizar una pirámide de acuerdo a la relevancia y la responsabilidad creativa de cada miembro del equipo de una serie de televisión, el director o realizador se encontraría sin duda por debajo del productor y el guionista. El director de televisión es tradicionalmente un "asalariado en un proceso de creación en cadena, que únicamente puede introducir su creatividad en la esfera de la planificación visual. Aunque en aquellas series donde el productor ejecutivo impone un modelo visual, su papel se limita a seguir los dictados generales de la producción" (Villagrasa, 1989:103).

Con la Segunda Edad Dorada de la televisión norteamericana, la figura del director cobrará mayor importancia, y entrará a formar parte activa de la faceta creativa de la serie. Será por supuesto en la cadena de pago HBO donde los realizadores lograrán aportar sus visiones personales desde las series más aclamadas por la crítica, mediante una sensibilidad cinematográfica que convertía cada episodio en un filme reducido. Nombres como Rodrigo García, Rose Troche o Miguel Arteta serán capaces de adquirir el control creativo suficiente para convertir la creación de otro en un proyecto propio. Estos directores saltarán además al cine, donde realizarán películas cuya estética y temática será similar a la de las series en las que trabajaron como realizadores.

A pesar de que en televisión, el medio pertenece al guionista (Wells, 1994:97) y el director ha ido adquiriendo un progresivo control creativo sobre las series que le ha permitido salir del ostracismo al que estaba condenado históricamente, será el nombre del productor ejecutivo o creador de la serie el que se encontrará por defecto a la cabeza de la carrera por la autoría de la obra. Si bien es cierto que muchos productores ejecutivos aportarán mucho más que su nombre al proyecto $-\mathrm{y}$ en estos casos el título de autor estará más justificado-, por regla general, el productor solo Admira $n^{\circ} 3-2011$ 
aportará la visión inicial, que deberá ser desarrollada por un equipo de guionistas y directores, con la misión de mantener una serie dentro de una visión homogénea y única -lo que contribuye por tanto a la atribución de la obra a una mente individual. No obstante, como hemos podido observar en los últimos años, la figura del showrunner o productor ejecutivo que se involucra día a día en el proceso creativo de la serie permitirá la consideración de un tipo de autor televisivo al cargo de todos los aspectos de su obra, es decir, un autor total. Como afirma Longworth Jr. (2002), estos creadores de televisión comienzan a formar un gran gremio de profesionales duchos en todos los aspectos económicos y artísticos del medio, y cuya fraternidad caracterizará la era del drama, demostrando asimismo que es posible insertar una voz propia en el impersonal entretenimiento comercial (Heil, 2002).

\section{Conclusiones}

Tras XX la cuestión de la autoría en el medio televisivo, y en concreto en el drama estadounidense, podemos concluir que es posible atribuir la responsabilidad creadora a una sola figura en un proceso de producción que involucra, sin excepciones, a grandes equipos de profesionales. En este estudio hemos comprobado cómo varios factores contribuyen a la identificación de estas figuras como autores de televisión. Y para ello, hemos partido de la teoría de André Bazin, desarrollada posteriormente por Cahiers du Cinéma, adaptándola pertinentemente al medio televisivo. De esta manera, hemos descubierto que mientras que en el medio cinematográfico se ha atribuido tradicionalmente la autoría de una obra a su director, en la televisión, es la figura del productor ejecutivo la que obtiene -aunque no en todos los casos- el título de autor, entendido como auteur -término que implica una voluntad creadora y artística, más allá del trabajo industrial. Asimismo, creemos posible demostrar una evolución en la figura del productor ejecutivo que resultaría en la noción de creador absoluto de una obra televisiva de larga duración tal y como hemos llegado a conocer en la hipertelevisión.

Para llegar a estas conclusiones, hemos analizado las perspectivas aportadas por varios investigadores en el ámbito de los medios de comunicación. Mientras unos autores hablan de una televisión moldeada por los productores ejecutivos -enlaces directos de los grandes cargos corporativos-, otros reivindican la labor artesanal del gremio de guionistas, para algunos verdaderos autores a la sombra. Sin embargo, Admira $n^{\circ} 3-2011$ 
como hemos comprobado en este estudio, esta dualidad es más compleja de lo que parece. Los guionistas de ficción televisiva, al igual que los directores, son, en la mayoría de casos, asalariados al servicio de un productor cuya visión inicial han de seguir en su trabajo para la serie. Ahora bien, es posible detectar señas de identidad en el trabajo de estos guionistas y directores -en especial en las series de televisión en las que estos se encargan de un gran número de episodios. Como hemos visto, algunos de los guionistas y directores más prolíficos de las décadas de los cincuenta y sesenta desarrollaron posteriores carreras cinematográficas o televisivas como autores Sidney Lumet, Rod Serling. Sin embargo, lo habitual será que el guionista o director sea una prolongación del productor ejecutivo, cuya premisa para la creación de su serie y sus intervenciones como guionista o director en la misma servirán como guía de trabajo para estas figuras del proceso de producción de ficción televisiva.

Volviendo a la teoría de los autores, podemos establecer paralelismos entre la noción del realizador cinematográfico como autor de cine y la del productor ejecutivo como autor de televisión. Del estudio de autores como Javier Maqua, Antoine De Baecque o Douglas Heil, hemos extraído cuáles son las características que definirán a un autor:

- El autor es el mayor responsable del resultado final, es la figura que aporta la unidad necesaria al trabajo en equipo de los profesionales involucrados en un proyecto.

- El autor ejerce sus dotes de mando y tiene en su poder la decisión final sobre todos los aspectos de la producción.

- El autor se encargará de aportar una visión personal y mantenerla a lo largo del proyecto, a pesar de la intervención en él de un gran número de profesionales.

- El autor repetirá motivos, arquetipos, rasgos estéticos y temas en todas sus obras.

Aplicando estas características a ambos medios, el cinematográfico y el televisivo, observamos cómo el director cumple estos requisitos en el cine, mientras que es el productor ejecutivo - o creador- el que se ajusta al perfil de autor que hemos trazado. De esta manera, el productor televisivo adquiere mayor consideración a medida que el drama televisivo gana terreno al cine y las nuevas obras catódicas se estrenan utilizando el nombre de su creador como potente reclamo publicitario. Los autores consagrados del cine crean historias para la televisión, y los productores televisivos 
adquieren el reconocimiento antaño únicamente reservado para los cineastas. Tras una década de drama norteamericano televisivo en el siglo XXI, se hace necesario hablar de un nuevo tipo de autor, hipermoderno y transmedial, que está redefiniendo el panorama de la ficción audiovisual norteamericana.

\section{Referencias bibliográficas}

Bazin, André (1974). La política de los autores. Madrid: Editorial Ayuso.

Cascajosa Virino, Concepción (2005). Prime Time. Las mejores series de TV americanas. De C.S.I. a Los Soprano. Madrid: Calamar Ediciones.

De Baecque, Antoine (compilador) (2003). La politica de los autores: manifiestos de una generación de cinéfilos. Barcelona: Paidós.

Fahy, Thomas (2005). Considering Aaron Sorkin: esays on the politics, poetics, and sleight of hand in the films and television series. Jefferson, N.C: McFarland \& Co.

Fahy, Thomas (2006). Considering Alan Ball: essays on sexuality, death and America in the television and film writings. Jefferson, N.C: McFarland \& Co.

Friedman, Julian \& Roca, Pere (1994). Writing Long-Running Television Series. Lectures from the first PILOTS Workshops. Barcelona: Media Business School.

Geraghty, Lincoln (2009). Channeling the Future. Essays on Science Fiction and Fantasy Television. Plymouth: The Scarecrow Press.

Gordillo, Inmaculada (2009). La hipertelevisión. Quito: Ciespal.

Heil, Douglas (2002). Prime-Time Authorship. Nueva York: Syracuse University Press.

Imbert, Gérard (2008). El transformismo televisivo. Postelevisión e imaginarios sociales. Madrid: Cátedra.

Jancovich, Mark \& Lyons, James (editores) (2004). Quality Popular Television. Londres: BFI Publishing.

Jiménez Losantos, Encarna \& Sánchez-Biosca, Vicente (1989). El relato electrónico. Valencia: Ediciones Textos Filmoteca Generalitat Valenciana.

Longworth Jr. , James L. (2002). TV Creators. Conversations with America's Top Producers of Television Drama. Volumes One \& Two. Nueva York: Syracuse University Press. 
Maio, Barbara (2009). La terza Golden Age della televisione. Cantalupo in Sabina (RI): Sabinæ.

Maqua, Javier (1992). El docudrama: Fronteras de la ficción. Madrid: Cátedra.

Marc, David \& Thompson, Robert J. (1995). Prime Time, Prime Movers. Nueva York: Syracuse University Press.

Newcomb, Horace \& Alley, Robert S. (1983). The Producer's Medium. Nueva York: Oxford University Press.

Newcomb, Horace (1994). Television. The Critical View. Nueva York: Oxford University Press.

Priggé, Steven (2005). Created By... Inside the Minds of TV's Top Show Creators. Beverly Hills: Silman-James.

Thompson, Robert J. (1997). Television's Second Golden Age: From Hill Street Blues to ER. Nueva York: Syracuse University Press.

VV.AA. (2009). Los Soprano forever: antimanual de una serie de culto. Madrid: Errata Naturae.

VV.AA. (2010). The Wire. 10 dosis de la mejor serie de la televisión. Madrid: Errata Naturae.

Wolf, Mauro (1987). La investigación de la comunicación de masas. Crítica y perspectivas. Barcelona: Paidós 